\title{
Is it ethical for doctors to google their patients?
}

\author{
Cite as: CMAJ 2019 April 1;191:E373-4. doi: 10.1503/cmaj.109-5725
}

Posted on cmajnews.com on Mar. 11, 2019.

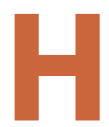
ard to believe that just two decades ago Google didn't exist. Today, it holds a place of honour in the dictionary - a verb embedded in every aspect of our lives. We google ourselves, our favourite restaurants, our destination before heading out for the evening. But should doctors google their patients?

A recent article in Forbes explored the implications of a survey led by Dr. Liliya Gershengoren, a professor of psychiatry at Cornell University. Her survey of 82 attending and resident physicians at a large academic medical centre found that " 93 percent of staff and 94 percent of residents reported googling a patient at least once, [and] that 17 percent of staff and 40 percent of residents googled their patients on a frequent or semi-regular basis in the ER."

In this day and age, it's no surprise that physicians might be tempted to google patients. But does that make it right? The personal information gleaned online is publicly available, but there are potential pitfalls to consider before doing that search.

A group of five Canadian doctors, including Dr. Maxim Ben-Yakov, were the first to publish a large-scale survey on this topic. That 2011 survey, in the Western Journal of Emergency Medicine, asked 530 Canadian emergency physicians and trainees whether they had looked up patients on Google or Facebook and their perceptions of the ethics of doing so. The question was sparked by a 2009 incident when Ben-Yakov was a student and encountered a patient about whom he had no information beyond a name.

"What came through in the survey comments was that googling might be useful in very specific circumstances like when there is a psychiatric presentation and you're trying to tell truth from

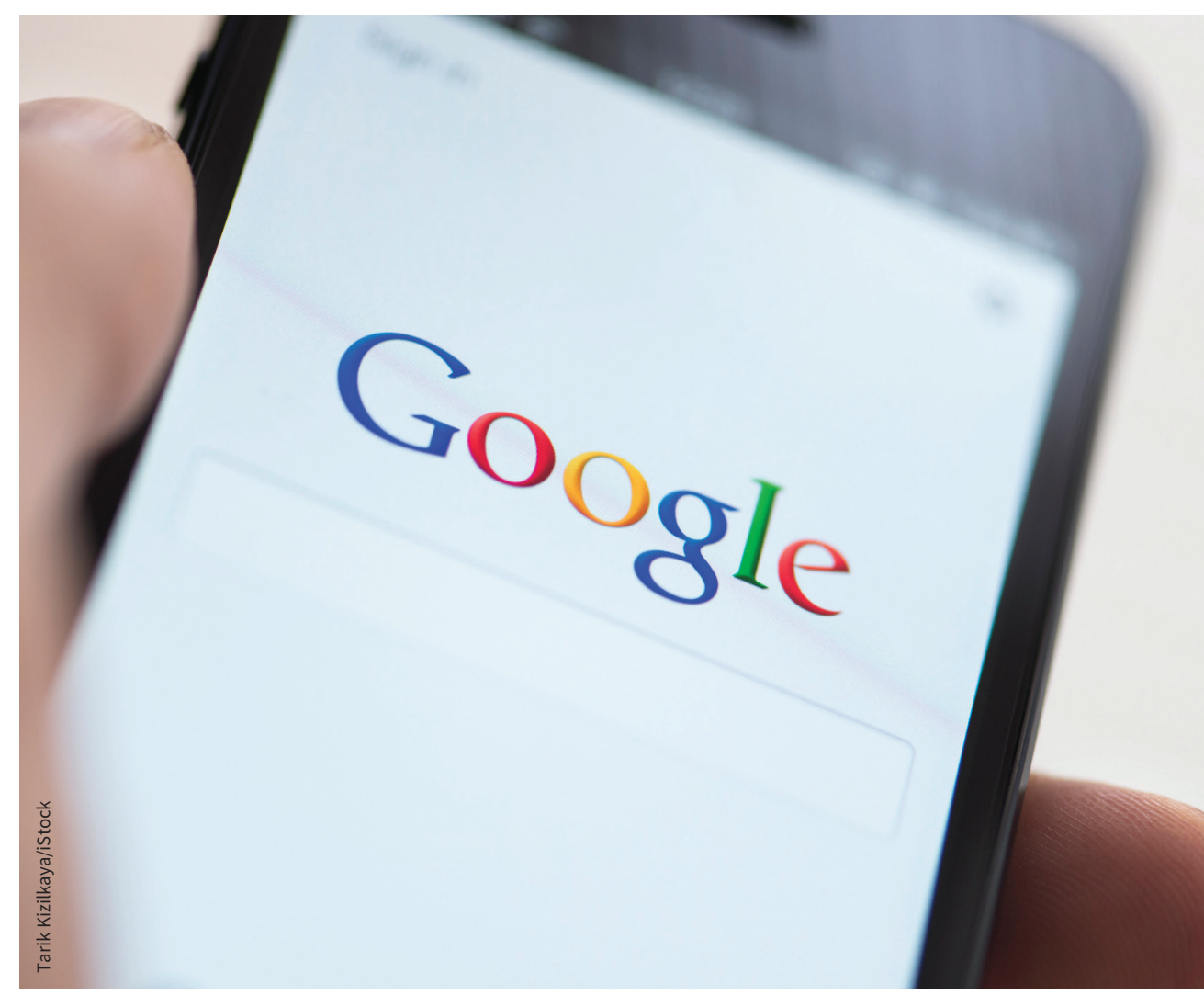

Some doctors believe googling patients can be useful in certain situations.

delusion," says Ben-Yakov, an emergency physician in Toronto. "But even then you have to be very careful. Some of what you find online may not reflect reality."

If electronic health records were better, he notes, googling a patient would almost never be necessary. "I won't even have to consider the ethics of googling if I have access to a patient's medications, lab work, and other information that gives me a better picture of their history even if they don't tell me."

Dr. Karen Devon, another contributor to the Canadian survey, believes googling should be formally addressed during medical training and codified through consensus guidelines. "In the absence of a patient's ability to consent [to an Internet search], we could establish guidelines about when searching is appropriate and how information ought to be assessed and used," says Devon, an assistant professor of surgery at the University of Toronto.

The physician-patient relationship is built on a foundation of trust, and "if a patient has things they do not want to disclose, even if that information would be helpful to the patient, that is the patient's prerogative and right. We ought to respect that," she says.

That view is echoed by Phoebe Friesen, a medical ethicist at the University of Oxford. Because it's unlikely that patients expect their doctors to google them, she 
says doing so violates both their privacy (their right to control information about themselves) and their autonomy (their ability to shape their care around their own values and desires).

Violations of patient privacy or autonomy should be deemed necessary only under extreme circumstances. An example would be a patient brought into an emergency room unconscious and requiring life-saving care but who cannot con- sent. In such cases, the violations would be considered justified because the benefits outweigh the harms.

Then there is the question of bias. Every doctor must guard against biases based on race, sexuality, socioeconomic status and gender. "It is worth asking: Is the information available online about patients likely to reinforce stereotypes that lead to differential treatment and increase inequalities in care?" says Friesen.
Though googling patients should be on the decline with better access to electronic records, it may never stop entirely. That's why current discussions are centred around when to google and how to mitigate the risks. "It is likely that guidelines will be developed in time," says Friesen. "At the moment, however, it's the Wild West."

Sarah Brown, Ottawa, Ont. 